\title{
Footedness in foraging muskoxen Ovibos moschatus
}

\author{
James A. SCHAEFER ${ }^{*}$ and François MESSIER
}

\begin{abstract}
Schaefer J. A. and Messier F. 1997. Footedness in foraging muskoxen Ovibos moschatus. Acta Theriologica 42: 335-338.

We investigated the propensity for wild muskoxen Ovibos moschatus (Zimmerman, 1780 ) to exhibit right or left bias in foreleg use while foraging during winter. We found little evidence of such lateralisation, either on the individual or population level. Only 3 of 40 animals exhibited significant right- or left-footedness, and the distribution across the population for use of either limb was near $50 \%$. Time-series analysis revealed that lateralisation of paw use was sequentially dependent. Muskoxen tended to use the same paw for one ensuring bout, but were also inclined to switch sides over durations of 4 bouts. The lack of lateral bias, at least for this behaviour, contrasts with the general, emerging pattern for the Mammalia.
\end{abstract}

Department of Biology, University of Saskatchewan, 112 Science Place, Saskatoon, SK, S7N 5E2, Canada

Key words: Ovibos moschatus, behaviour, footedness, lateralisation

\section{Introduction}

The study of lateralised animal structure and function is central to the understanding of evolutionary relationships. For example, asymmetry of limb preference is well-documented for humans, but the exent of homologous lateralisation amongst the Mammalia remains unclear. In a comprehensive review, Bradshaw and Rogers (1993) concluded that lateralised behavioural biases were not uncommon for vertebrates (eg, Rogers and Workman 1993, Bisazza et al. 1996) including mammals (eg, Hook-Costigan and Rogers 1995, Anderson et al. 1996). For mammals, however, they noted the fragmentary nature of the evidence, exclusive of Rodentia and Primates. For ungulates, with a few exceptions (Jarman 1972, Thing 1977, Grant et al. 1990, Ganskopp 1995), there is a paucity of data on lateral biases.

The burgeoning evidence on lateralisation has been amassed largely through laboratory experiments. Nevertheless, its validity rests on a critical assumption, viz, that artificial trials provide symmetrical sensory input to the animal (Davies and Green 1991). There is a particular need, therefore, for observations under

\footnotetext{
*Present address: Wildlife Division, Government of Newfoundland and Labrador, P.O. Box 3014, Station B, Goose Bay, NF, A0P 1E0, Canada; fax: (709) 896-0188, e-mail: wildlife@cancom.net
} 
natural conditions. For example, Thing (1977) reported that wild caribou preferentially used their right forelegs to crater through snow cover while foraging.

Here, we examined lateralisation of foreleg movements by wild muskoxen Ovibos moschatus (Zimmerman, 1780) in the High Arctic. Like caribou, muskoxen regularly use their forelegs to uncover subnivean forages during winter. We examined lateralisation of foreleg use at both the individual and population levels. Furthermore, by applying time-series analysis to our observations, we investigated the degree to which lateralised paw use by foraging muskoxen exhibited temporal dependence.

\section{Methods}

We observed muskoxen in the vicinity of Wellington Bay $\left(69^{\circ} 25^{\prime} \mathrm{N}, 106^{\circ} 15^{\prime} \mathrm{W}\right)$ in the Canadian Arctic during periods of snow cover, ie November 1992 and early April to late May, 1992 and 1993. Focal animals were observed for approximately 30 min each using $30 \times$ spotting scopes, 200-1500 m away. For each animal, we noted each pawing movement with the left or right foreleg and recorded events on audio tape. The data were transcribed using ANSCAN ver. 1.4, a computerised event recorder.

Pawing acts by muskoxen, while cratering, are strongly clustering into bouts (Schaefer and Messier 1995). We used the pawing bout - with a minimum separation interval of $2.3 \mathrm{~s}$ between pawing acts, determined by the log-frequency procedure (Schaefer and Messier 1995) - as the unit for further analysis. Each bout was classified as left or right, regardless of the number of pawing acts that it comprised. Bouts involving the use of both legs were rare ( $2.0 \%$ of 1515 bouts) and were discarded. For population-level analysis, we avoided the common error (eg Davies and Green 1991) of pooling the data (Machlis et al. 1985) and instead used each animal as the experimental unit. In total, we observed 40 animals, each displaying at least 12 pawing bouts during the observation period.

Data were analysed for lateral bias using non-parametric methods (Siegel and Castellan 1988). To examine the temporal organisation of the behaviour, we used time-series analysis (SPSS Inc. 1993). For each animal, we estimated the autocorrelation function (ACF) from left (0) and right (1) scores, then plotted the average ACF for lags up to 5 bouts.

\section{Results and discussion}

We found little evidence of footedness, either on individual or population levels. On the level of the individual, we searched for possible lateral biases by applying a binomial test to the numbers of left and right bouts for each animal. We found that only 3 of 40 animals displayed any significant lateral bias (binomial tests, $p<0.05,12 \leq n \leq 78$ ). Similarly, the population exhibited a symmetrical, unimodal distribution of footedness, close to being centred on $50 \%$ use of either limb (Fig. 1).

Although neither individual nor population biases were evident, we found that the temporal sequence of limb use was non-random. This pattern was not evident at the individual level, perhaps due to the low statistical power at small sample sizes. We found just 2 of 40 individual cases of temporal non-randomness (one-sample runs tests, $p<0.05$ ), implying sequential independence between left and right bouts. Temporal structure of forelimb use, however, was revealed by 


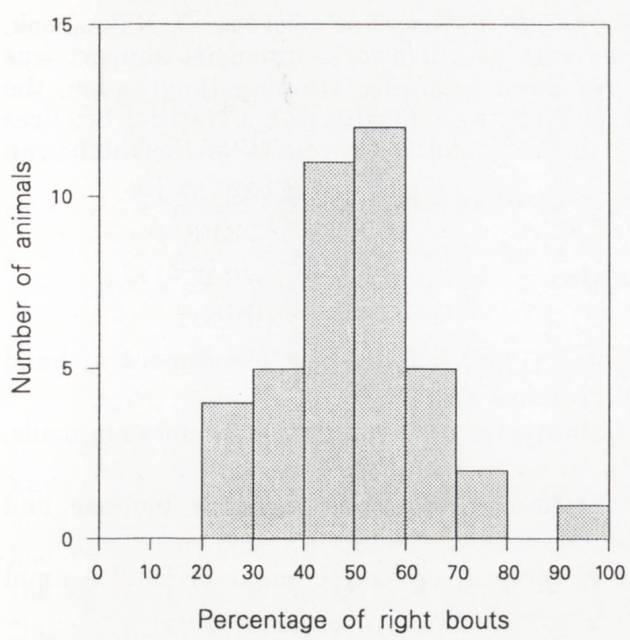

Fig. 1. Distribution of left/right paw preference by foraging muskoxen.

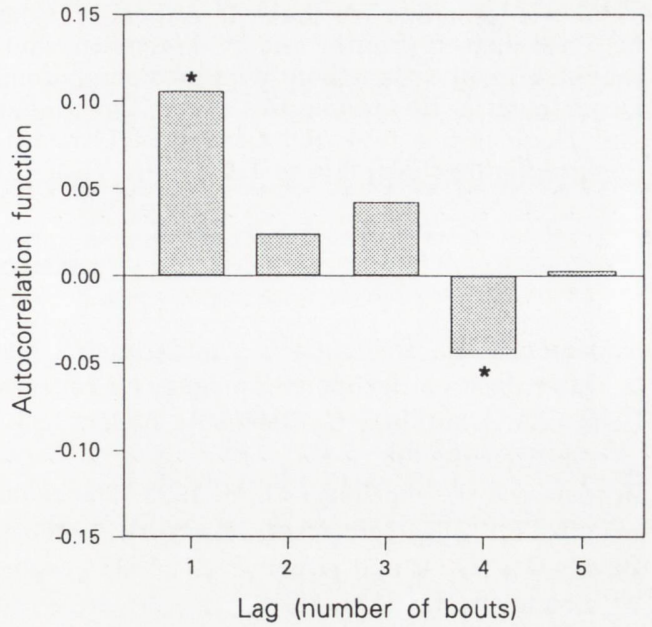

Fig. 2. Temporal autocorrelation of left/right pawing bouts by muskoxen. Values significantly different from zero $(p<0.10)$ are indicated by *.

time-series analysis. ACF was positive $(p<0.05)$ for the first ensuing bout, but decayed and became marginally negative $(0.05 \leq p \leq 0.10)$ when the lag increased to 4 bouts (Fig. 2). This indicated that muskoxen generally used the same limb for one successive bout, but tended to switch between forelimbs over longer periods.

On a population level, the lack of lateral bias by muskoxen - at least with respect to this behaviour - generally contrasts with the emerging pattern for non-rodent, non-primate mammals (Walker 1980, Bradshaw and Rogers 1993). Amongst bovids, Jarman (1972) noted a right-sided tendency for injuries from aggressive encounters in impala and Grant et al. (1990) reported on a left-side selection in cows while lying and ruminating. Hosoi et al. (1995a, b) also remarked on individual lateral preferences in T- and Y-mazes for goats, sheep, and cows, but they further suggested that such biases might have been artefacts of the artificial environment. Indeed, Ganskopp (1995) documented an absence of turning bias, for both individuals and the population, in free-ranging angora goats while foraging. Nevertheless, we cannot dismiss the possibility that muskoxen may exhibit forelimb bias under varying nival conditions, for example.

Our results contrast with Things (1977) observations on caribou, who documented a slight bias (ie, 53.16\% of all pawing acts) toward right-pawedness. Nonetheless, we hypothesise that, with respect to large herbivore foraging - where favourable food patches are liable to appear irrespective of side - lateral asymmetry is unlikely to be favoured. Overall, we concur with Bradshaw and Rogers (1993) that more evidence will be required before the patterns of lateral asymmetries in non-primate and non-rodent Mammalia can be widely generalised. 
Acknowledgements: We thank R. Akhok, M. Campbell, S. Côté, P. Fargey, C. Gordon, D. Nakashook, M. Pidkovich, J. Smith, and A. Wamekon who helped with the fieldwork. Financial support was provided by the Canadian Wildlife Foundation, the Northern Scientific Training Programme, the Department of Renewable Resources (Government of the Northwest Territories), a Natural Sciences and Engineering Research Council of Canada grant to F.M., and a University of Saskatchewan Postgraduate Scholarship to J.A.S.

\section{References}

Anderson J. R., Degiorgio C., Lamarque C. and Fagot J. 1996. A multi-task assessment of hand lateralization in capuchin monkeys (Cebus apella). Primates 37: 97-103.

Bisazza A., Cantalupo C., Robins A., Rogers L. J. and Vallortigara G. 1996. Right-pawedness in toads. Nature 379: 408.

Bradshaw J. L. and Rogers L. J. 1993. The evolution of lateral asymmetries, language, tool use, and intellect. Academic Press, New York: 1-463.

Davies M. N. O. and Green P. R. 1991. Footedness in pigeons, or simply slight of foot? Animal Behaviour 42: 311-312.

Ganskopp D. 1995. Free-ranging angora goats: left- or right-handed tendencies while grazing? Applied Animal Behaviour Science 43: 141-146.

Grant R. J., Colenbrander V. F. and Albright J. L. 1990. Effect of particle size of forage and rumen cannulation upon chewing activity and laterality in dairy cows. Journal of Dairy Science 73: 3158-3164.

Hook-Costigan M. A. and Rogers L. J. 1995. Hand, mouth and eye preferences in the common marmoset (Callitrix jacchus). Folia Primatologica 64: 180-191.

Hosoi E., Rittenhouse L. R., Swift D. M. and Richards R. W. 1995a. Foraging strategies of cattle in a Y-maze: influence of food availability. Applied Animal Behaviour Science 43: 189-196.

Hosoi E., Swift D. M., Rittenhouse L. R. and Richards R. W. 1995b. Comparative foraging strategies of sheep and goats in a T-maze apparatus. Applied Animal Behaviour Science 44: 37-45.

Jarman P. J. 1972. The development of the dermal shield in impala. Journal of Zoology, London 166: 349-356.

Machlis L., Dodd P. W. D. and Fentress J. C. 1985. The pooling fallacy: problems arising when individuals contribute more than one observation to the data set. Zeitschrift für Tierpsychologie 68: 201-214.

Rogers L. J. and Workman L. 1993. Footedness in birds. Animal Behaviour 45: 409-411.

Schaefer J. A. and Messier F. 1995. Winter foraging by muskoxen: a hierarchical approach to patch residence time and cratering behaviour. Oecologia 104: 39-44.

Siegel S. and Castellan N. J., Jr 1988. Nonparametric statistics for the behavioral sciences. McGraw-Hill, New York: 1-399.

SPSS Inc. 1993. SPSS/PC+ trends, version 5.0. SPSS, Chicago: 1-465.

Thing H. 1977. Behavior, mechanics and energetics associated with winter cratering by caribou in northwestern Alaska. University of Alaska, Fairbanks, Biological Paper 18: 1-41.

Walker S. F. 1980. Lateralization of function in the vertebrate brain: A review. British Journal of Psychology 71: 329-367.

Received 7 October 1996, accepted 30 April 1997. 